\title{
5 \\ Capital Social y Cooperativas \\ en los Países Escandinavos
}

\author{
José M. ${ }^{a}$ Montolío \\ Dr. en Derecho \\ Abogado
}

Las referencias que seguidamente se hacen se circunscriben a los cuatro países escandinavos -Dinamarca, Finlandia, Noruega y Suecia- que, por razones históricas y culturales, ofrecen unas más que apreciables afinidades. Una situación comparable se ofrece desde la perspectiva de las cooperativas, tanto en lo que se hace al origen y evolución de estas entidades como al tratamiento legislativo de que son objeto, por mucho que pudiera resultar alejadas al cooperativismo de la Europa del Sur.

Esta apreciación inicial no garantiza, sin embargo, que no hayamos de encontrar desencuentros notables. El primero, quizá, que dos de estos países - Dinamarca y Noruega - carecen de legislación específicamente cooperativa; el segundo, quizá, que Noruega rehusó en su momento a integrarse en la Unión Europea.

\section{Un concepto compartido: las cooperativas son entidades para la promoción económica de sus miembros}

El hecho de que Dinamarca no haya promulgado una legislación específica para las cooperativas — por mucho que el relegado proyecto de 1986 parezca avivarse periódicamente - no significa que la figura cooperativa resulte extraña. La solución dada por el ordenamiento danés - sustentado poderosamente en el sustrato ideológico de evitar separaciones- es que las cooperativas pueden servirse de cualquiera de las fórmulas societarias existentes, adoptando vía estatutos las determinaciones condignas con su naturaleza. 
De esta manera las cooperativas vienen normalmente revestidas de la forma de una sociedad anónima («Aktieselskab», abreviadamente «A/S») o de una sociedad de responsabilidad limitada («Anpartsselskab», abreviadamente "ApS»). La peculiar forma de asociación de responsabilidad limitada ("Andelsselskab med begroenset ansvar», abreviadamente "Amba»), que tuvo su mayor acogida en el medio rural, es hoy menos frecuente. Ahora bien, por vía estatutaria - las entidades de integración cooperativa adquieren en este punto un protagonismo de primer orden- adoptan aquellas determinaciones propias del funcionamiento cooperativo.

Pues bien, el concepto de cooperativa es inseparable del de empresa, entidad económica y del propósito de promoción económica de sus socios. La influencia de la venerable Ley Schulze con su traslación a la vigente Ley alemana de 1889 es innegable.

Del todo similar puede considerarse la solución adoptada por la legislación de Noruega donde el concepto de cooperativa está plenamente aceptado («Samvirkelag») como asociación con finalidad económica, adoptando formalmente cualquiera de las formas societarias admitidas por el Derecho de sociedades. Se tratará, normalmente, de una sociedad de responsabilidad limitada («Aksjeselskap», abreviadamente AS). ${ }^{1}$

En el caso de Finlandia y desde la primera Ley de cooperativas de 1901, por mucho que se destacara el carácter personalista de la cooperativa, la conclusión es la misma directamente ya desde el Derecho positivo. El artículo 1 de la vigente Ley 247 de 28 de mayo de 1954 establece que es objeto de la cooperativa («Osuuskunta», aquí una entidad propia y distinta de cualquier otra de naturaleza societaria o no) promover los intereses económicos de sus socios mediante la realización en común de actividades económicas en que aquellos participen.

La legislación de Suecia coincide plenamente con la que acaba de exponerse, cupiendo remontarnos a la vetusta Ley de 1895 sobre asociaciones de finalidad económica. ${ }^{2}$ La cooperativa («Economisk forening»,

1 No se contempla el habitual dualismo entre sociedades anónimas y sociedades de responsabilidad limitada.

2 El carácter tributario de esta legislación con relación a la Ley alemana se evidencia de nuevo. La legislación de Suecia no se refería a cualquier asociación de finalidad económica sino a aquellas que resultaren «registradas». La misma determinación de la Ley alemana cuya regulación no recae sobre cualquier cooperativa sino sobre las «cooperativas registradas» («Eingetragene Genossenschaft», abreviadamente «eG»). 
abreviadamente «Ek. for», una sociedad distinta y diferenciada de cualquiera otra de las acogidas por el ordenamiento) ha de perseguir desde el texto de la vigente Ley de 11 de junio de 1987 (Cap. I, § 2) promover los intereses económicos de sus socios por medio de cualquier actividad de tal naturaleza.

\section{El capital social}

Como fácilmente cabe colegir, en los ordenamientos de Dinamarca y Noruega el tratamiento del capital social dependerá necesariamente de las reglas establecidas para el tipo societario bajo cuya forma se constituya la cooperativa.

La legislación danesa exige en cualquier caso el otorgamiento de escritura pública y la formación de los estatutos por los que ha de regirse la sociedad. Entre las previsiones que han de contener los estatutos está la determinación del valor nominal de las acciones y el régimen de las mismas, concretándose si han de ser nominativas o no y si tendrán, o no, la condición de negociables.

Una disposición similar rige en la legislación de Noruega. La constitución de la sociedad pasa por el otorgamiento, por mucho que no se exija formalidad notarial, de un acta fundacional a la que unirán los estatutos por los que ha de regirse la entidad. Entre los contenidos inexcusables de éstos figura la determinación del capital social, valor nominal de las acciones y su régimen.

La Ley de cooperativas de Finlandia obliga a la constitución de la sociedad mediante escritura pública en la que constarán los estatutos de la misma. El principio de variabilidad del capital se reconoce expresamente en la Ley desde la propia conceptuación de la cooperativa y del mismo modo se reserva su suscripción a los socios.

Los estatutos, por su parte, han de fijar el valor nominal de cada acción de las que integran el capital social así como el plazo para su desembolso que deberá llevarse a cabo en términos de igualdad para todos los socios. La condición de socio se vincula a la suscripción de la acción o acciones que vinieran determinadas y, en principio, las acciones no son trasmisibles.

Por el contrario de estas acciones o aportaciones que pudiéramos denominar obligatorias, la Ley (Cap. 17.A) regula la posibilidad de que 
los socios puedan efectuar acciones o aportaciones adicionales que pueden gozar de beneficios de índole económica especiales.

La Ley de sociedades cooperativas de Suecia participa de la sistemática expuesta hasta el momento. En primer lugar la Ley no obliga a la formalización de la carta fundacional en escritura pública y no distingue tampoco entre aquella y los estatutos por los que haya de regirse la cooperativa. Ahora bien, en el acta fundacional y en las reglas que en la misma se estipulen han de regularse las aportaciones económicas de los socios al capital de la cooperativa.

Al establecerse la oportuna regulación de este extremo, la Ley prevé que se distinga entre las aportaciones de carácter obligatorio para acceder a la condición de socio —normalmente se denominan acciones- y las aportaciones voluntarias que pudieren establecerse. En principio, la Ley no establece limitaciones a la transmisibilidad.

\section{Otras previsiones de índole económico financiera}

Los dos países de los que nos ocupan que disponen de Ley de cooperativas resultan en definitiva parcos a la hora de regular otros instrumentos financieros del orden de los que la legislación europea más moderna nos ofrece. ${ }^{3}$

De esta manera, la Ley de cooperativas de Finlandia se limita a prever el que denomina "capital social de inversión» (Cap. 18) integrado por aportaciones netamente financieras, trasmisibles y sin derecho a voto.

Establece así mismo la Ley que los estatutos puedan arbitrar cuotas o pagos análogos con motivo del ingreso e incluso derramas extraordinarias para atender una necesidad societaria inexcusable. En este punto, sin embargo, la Ley prohíbe (art. 7) que los estatutos se sirvan de cláusulas inespecíficas o del todo abiertas.

La Ley de sociedades cooperativas de Suecia se limita a permitir que los estatutos amparen cuotas ordinarias o derivadas de causas

3 Sin hacer ahora referencia particularizada a los múltiples ejemplos que como más recientes nos muestra la legislación española, baste recordar la tendencia seguida con carácter prácticamente generalizado desde la reforma alemana de 1973, Ley de modernización francesa de 1992, reforma italiana del mismo año, nuevo Código portugués de 1996, etc ... 
especiales, siempre determinadas, así como que estas sociedades emitan obligaciones (Cap. 5) sujetándose al régimen previamente establecido al efecto y que puede entrañar limitaciones a su libre transmisibilidad.

Por lo que se refiere a Dinamarca y Noruega, salvo la autorregulación estatutaria, el régimen aplicable a las sociedades cooperativas no entraña especialidad alguna con el establecido con carácter general para el común de las sociedades.

\section{Sucintas conclusiones}

La somera aproximación que precede al régimen del capital social en la regulación de las sociedades cooperativas de los cuatro países escandinavos a que se ha hecho referencia ${ }^{4}$ nos conduciría a concluir que:

1. La conceptuación empresarial, económica, de promoción de intereses económicos de las cooperativas es connatural en todos ellos. La influencia de la legislación alemana se hace en este punto manifiesta.

2. ${ }^{\circ}$ Dispongan o no de Ley especial para estas entidades, el capital social es inexcusable en las mismas tanto desde el punto de vista de su concepto empresarial como desde la perspectiva del socio que necesariamente ha de participar en él.

3. Hay una evidente tendencia de exclusivizar en el socio la participación en el capital social.

4. ${ }^{\circ}$ No se ha recepcionado por el momento la tendencia generalizada en orden a incrementar y mejorar los instrumentos financieros de las sociedades cooperativas.

4 Para mayor detalle puede acudirse a mi trabajo Legislación cooperativa en la Unión Europea, 2. ${ }^{a}$ ed, Madrid 2000, y a los textos legales y bibliografía allí incluida. 